\title{
Un paso en el lento ascenso hacia la Doctrina de la ciencia. Introducción a J. G. Fichte, Reseña de Creuzer
}

Vicente Serrano

\section{(2) OpenEdition}

Journals

Edición electrónica

URL: http://journals.openedition.org/ref/564

DOI: $10.4000 /$ ref.564

ISSN: 2258-014X

Editor

EuroPhilosophie Editions

Referencia electrónica

Vicente Serrano, « Un paso en el lento ascenso hacia la Doctrina de la ciencia. Introducción a J. G. Fichte, Reseña de Creuzer », Revista de Estud(i)os sobre Fichte [En línea], 9 | 2014, Publicado el 28 diciembre 2014, consultado el 25 septiembre 2020. URL : http://journals.openedition.org/ref/564 ; DOl : https://doi.org/10.4000/ref.564

Este documento fue generado automáticamente el 25 septiembre 2020

(c) EuroPhilosophie 


\title{
Un paso en el lento ascenso hacia la Doctrina de la ciencia. Introducción a J. G. Fichte, Reseña de Creuzer
}

\author{
Vicente Serrano
}

1 La reseña que presentamos es un escrito menor de Fichte, una reseña de apenas unas pocas páginas aparecida en la "Jenaer Allgemeine Literatur-Zeitung" en el año 1793. Sin embargo, si uno quiere comprender la génesis de la idea fundamental que dio lugar a la Doctrina de la Ciencia de Fichte, y que de algún modo ya no abandona en ninguna de sus presentaciones hasta su muerte, más allá incluso de los cambios profundos en la terminología, debe tener en cuenta este escrito, junto con las otras dos reseñas que publica con muy poca diferencia de tiempo, la de Gebhard y la de Enesidemo. Ciertamente esta última ha recibido siempre una mayor atención al aparecer en ella, por primera vez, el término Tathandlung. Una cierta tendencia mitologizante nos podría hacer pensar que se trató de una especie de descubrimiento, análogo tal vez al descubrimiento cartesiano de la geometría analítica que supuestamente habría tenido lugar en un sueño en una noche de noviembre del año 1619. Pero nada más lejos de algo como una visión repentina. De hecho, esa primera alusión a la Tathandlung es el resultado de un largo proceso de elaboración que debe llevarnos al menos hasta el año 1792 y a la segunda edición de la Crítica de la Revelación, en cuyo nuevo parágrafo 2 se contiene un verdadero hallazgo que ya no abandonará Fichte.

2 Nos hemos ocupado de ello hace años, casi en las mismas fechas en que vio la luz una primera versión de esta traducción, en un artículo que llevaba por título Las tres reseñas de Fichte del otoño de 1793 y luego también con algún detalle en el capítulo 4 de Metafísica y filosofía trascendental en el primer Fichte. En esta última obra señalábamos una secuencia de la trayectoria de Fichte entre la Crítica de la Revelación y la Reseña de Enesidemo en los siguientes términos:

3 "En la Reivindicación de la libertad de pensamiento Fichte confirma, mediante una argumentación que es en realidad trasunto de la que ya había utilizado en el parágrafo 7 de la Crítica de la revelación, el carácter fundamental de la práctica respecto de la 
experiencia, y hace residir en ello lo característico del hombre frente al mecanismo. En el Escrito sobre la revolución francesa establecía ya una clara distinción entre hecho y 'ley eterna', de manera que sólo ésta última, entendida de modo coincidente con la ley moral, podía ocupar el lugar del principio. Así las cosas, el principio de conciencia de Reinhold no podía por menos de aparecer a los ojos de Fichte como un principio teórico $\mathrm{y}$, por tanto, incapaz de fundamentar la filosofía. Pero un principio de estas características es por definición un principio incapaz de fundar, esto es, de explicar transcendentalmente, el mundo moral. Esto es lo que Fichte demuestra en la Reseña a Creuzer"

4 Si nos hemos permitido una cita tan larga es porque, incluso a pesar de los años transcurridos, nos parece que contiene un buen resumen y presentación del significado, no menor, de la reseña de Creuzer. Fichte polemiza allí aparentemente con un escrito del por entonces joven teólogo Leonard Creuzer, quien acababa de publicar ese mismo 1793 una obra titulada Consideraciones escépticas sobre la voluntad. Con referencia a las últimas teorías sobre la misma. Polemiza además también con el prologuista de la obra, K.Ch. E Schmid. Pero, como Fichte mismo afirma al final de la reseña, estamos ante una obra inmadura y en sí misma casi carente de interés, más allá de la constatación del hecho mediante el cual arranca: la idea de que el escepticismo sirve de estímulo a la verdad, argumento que usará también de manera notable en la Reseña de Enesidemo.

5 Lo interesante es entonces precisamente la segunda parte del título de la obra de Creuzer, la que afecta a las últimas teorías sobre la voluntad, entre las que Fichte todavía no puede encontrar la que ha empezado a elaborar precisamente en el nuevo parágrafo 2 de la Crítica de la Revelación, pero si las de Kant, Heydenreich y Reinhold. No había, pues, mejor ocasión para afinar su propia teoría frente a todas ellas, y especialmente frente a Reinhold, cuya lectura está siendo decisiva para él en estos momentos en sus Eigne Meditationen, que nunca publicó y que constituyen un verdadero laboratorio de su pensamiento y una minuciosa reflexión sobre la filosofía elemental de Reinhold y sobre la posibilidad de reconstruir el kantismo a partir de un principio. Por tanto, esta reseña, como la de Gebhard, era una magnífica coyuntura para afinar y contrastar en pequeñas dosis, pero ya públicamente, sus diferencias con Reinhold a partir de su propia teoría, que viene trabajando de forma silenciosa y casi heroica en esas Meditaciones personales. Habiendo asumido la posibilidad y la necesidad de completar el sistema de Kant, tal como proponía Reinhold, se da cuenta bien pronto de que el principio de Reinhold es insuficiente. En la reseña de Creuzer esto aparece por primera vez expresado en los siguientes términos: "Reinhold ha rechazado ya, por cierto, esa posible contradicción, pero según la convicción del reseñante, que confiesa un total respeto por el gran pensador, ni ha mostrado la causa del malentendido, ni la ha sacado a la luz".

6 Es, como señalamos, la primera constancia que tenemos de una discrepancia o de una crítica por parte de Fichte a Reinhold. Y esa discrepancia tiene que ver nada menos que con la distinción entre "el determinar, en cuanto acción libre del Yo inteligible, y la determinación, como situación fenoménica del yo empírico". Es decir, entre un hecho y un algo que no es ni puede ser un hecho, sino que constituye "un verdadero querer", una instancia "autodeterminante", una especie de "armonía preestablecida" capaz de reunir necesidad y libertad. Ese algo es lo que Reinhold no ha alcanzado a pensar aún. Fichte solo lo apunta aquí. En la reseña de Gebhard hablará ya de un principio de la 
filosofía y en la de Enesidemo explicitará finalmente mediante el término Tathandlung la conclusión de un argumento cuyas premisas estaban dadas en las dos reseñas anteriores. Lo que aquí presentamos es entonces parte de un largo razonamiento que se inicia al menos en 1792 y que encuentra una primera culminación en el año 1794, pero que continúa luego de forma ininterrumpida en sucesivas presentaciones.

7 En Valdivia, Isla Teja. Diciembre de 2014

NOTAS

1. SERRANO MARÍN, V. (2004), Metafísica y filosofía transcendental en el primer Fichte, Valencia: Universidad Politécnica de Valencia, 2004, p. 84.

\section{AUTOR}

\section{VICENTE SERRANO}

Universidad Austral de Chile 